\title{
Treatment of Scoliosis by Hartshill Rectangle and Sublaminar Wiring
}

\author{
Md. Kamrul Ahsan', Najmus Sakeb², Naznin Zaman ${ }^{3}$, Abdullah Al Mahmud ${ }^{4}$ \\ ${ }^{1}$ Associate Professor, Department of Spinal Surgery, ${ }^{2}$ Resident, Department of Orthopaedic Surgery, Bangabandhu Sheikh Mujib Medical \\ University, ${ }^{3}$ Medical Officer, Department of Anaesthesiology, National Institute of Kidney Diseases and Urology, ${ }^{4}$ Lecturer, Department \\ of Pathology, Ibn-Sina Medical College.
}

\begin{abstract}
:
Background: Scoliosis is a complex three dimensional deformity characterized by coronal, sagittal and horizontal plane deviation. Treatment of scoliosis has made significant development in techniques and modalities of internal fixation. Objective: To see the efficacy of Hartshill rectangle and sublaminar wiring for correction of scoliotic deformity, clinical outcome and patient's satisfaction. Methods: During the period of July 2008 to June 2011, 14 patients of scoliotic spinal deformities of various etiologies (Congenital-02, idiopathic-12) were operated. Age ranged from 11 to 23 years with mean $16.71 \pm 03.22$ years. Female 09 and male 05 patients were included where Hartshill rectangles with sublaminar wiring were used for every case. Results: At least 12 months (range 12-36 months) follow up regarding clinico-radiological evaluation and patient's satisfaction were accounted as per the SRS-24 questionnaire. The mean scoliosis in the coronal plane (Cobb's angle) measured $53.50^{\circ} \pm 03.98^{\circ}$ preoperatively reducing significantly to $21.14^{\circ} \pm 02.77^{\circ}(\mathrm{p}<0.05)$ and the mean preoperative sagittal plane angle $60.14^{\circ} \pm 07.30^{\circ}$ reducing significantly to average $42.14^{\circ} \pm 05.28^{\circ}(p<0.05)$ at 1 year as determined by paired t-test. No neurological complication was seen except transient hyperesthesia in 02 patients, superficial wound infection in 01 patient and 01 wire breakage. All the patients were happy to live with their present back status. Conclusion: Overall outcome in segmental spinal fixation with sublaminar wire and Hartshill rectangle is satisfactory and effective.
\end{abstract}

Key words: Scoliotic deformities, Hartshill rectangles with sublaminar wiring, Cobb's angle.

[BSMMU J 2012; 5(1):6-11]

\section{Introduction:}

Scoliosis is a triplanar deformity with lateral, anteroposterior and rotational component. ${ }^{1}$ Most cases have no obvious cause (Idiopathic scoliosis); other varieties are osteopathic (congenital), neuropathic, myopathic and few have associated connective tissue disorders. ${ }^{2}$ Management differs for the different types of scoliosis ${ }^{2}$ but there is no data which support the view that brace or exercise can alter the natural history of scoliosis permanently. ${ }^{3}$

The surgical correction of scoliosis is marked with Paul Harrington introducing Harrington rod instrumentation in 1955. ${ }^{4}$ Since then there has been a tremendous improvement in the instrumentation techniques for correction of scoliosis. The posterior instrumentation technique advanced from two-point fixation to segmental fixation. ${ }^{5}$ The concept of segmental fixation was pioneered by Resina and Ferreira ${ }^{6}$ in 1963 by fixation with segmental wiring for the treatment of scoliotic curves. Luque and $\mathrm{Cardozo}^{7,8}$ popularized the sublaminar wires to attach to

Address for Correspondence: Dr. Md. Kamrul Ahsan, Associate Professor, Department of Spinal Surgery, Bangabandhu Sheikh Mujib Medical University, Shahbag, Dhaka, Bangladesh
L-shaped rods in1970s. Later the wiring of the apical vertebrae to the Harrington rod became a popular modality to correct coronal spinal deformities in the early 1980s. Hartshill rectangle was introduced by Dove ${ }^{9}$ in 1986. Although posterior surgical techniques have been shown to provide a limited correction of the deformity in only one plane and leaving the rotational hump, ${ }^{10}$ significant correctability and ability to maintain correction in all planes can be achieved by locally made stainless steel Hartshill loop rectangle and sub laminar wires. ${ }^{11}$

Although segmental spinal instrumentation by sublaminar wiring and Hartshill loop rectangle, had fallen out of favor in comparison to the newer third generation implants ${ }^{11}$, it is still considered a method of choice of surgical correction of scoliotic deformities. ${ }^{12,13,14}$ The field of scoliotic surgery has long been unexplored in our country due to lack of expertise as well as costly and relatively unaffordable price of the implants. As cost of implants had been a major issue for most of our patients, in our socio-economic aspect we have chosen to evaluate the efficacy of low cost locally made Hartshill rectangle and sublaminar wires as a modality for correction of scoliotic deformity and its co-relation with patients' satisfaction and clinical outcome. 


\section{Methods:}

The study is performed prospectively from July 2008 to June 2011 in Bangabandhu Sheikh Mujib Medical University and a private hospital in Dhaka. We have evaluated the surgery on 14 consecutive scoliotic patients of different etiologies which includes 12 cases of Adolescent Idiopathic Scoliosis (AIS) and 02 cases of congenital scoliosis. There were 09 female and 05 male presenting within an age ranging from 11 to 23 years with a mean age of $16.71 \pm 03.22$ years. The patients in idiopathic type were further sub classified according to King's and Moe's classification system as Type-2 (04 patients) and Type-3 (08 patients). There were no patients with King's and Moe's Type-1, Type-4 and Type-5. Ten patients presented with right convex curve and 04 with left sided convexity.

All the patients were evaluated clinically [Figure-1(a), (c)] as well as radiologically by doing a scoliogram film in standing posture $\mathrm{P} / \mathrm{A}$ view extending from $\mathrm{C}_{2}$ to $\mathrm{S}_{2}$ as well as a lateral view in supine position of the same extent. The right and left lateral bending views were also evaluated preoperatively [Figure-1(e)]. These key radiological images were helpful in determining the Cobb's angle, sagittal profile, flexibility of the spinal column as well as determining the extent of fusion. The average preoperative Cobb's angle was $53.50^{\circ}$. The saggital profiles of all the patients were measured between $T_{2}-T_{12}$ for thoracic kyphosis and $\mathrm{L}_{1}-\mathrm{S}_{1}$ for lumbar lordosis. The normal thoracic kyphosis was taken as $20^{\circ}-40^{\circ}$ and lumbar lordosis as $40^{\circ}-60^{\circ}$. In our patients the thoracic curves averaged $60.14^{\circ}$ and the lumbar curves $44^{\circ}$.

The patients with the following criteria had been included for the study, i) Cobb's angle $>40^{\circ}$; ii) Progressive increase of the Cobb's angle $>10^{\circ}$ in successive 6 months follow up; iii) Patients demand for surgery for cosmetic purpose. The exclusion criteria for the patients had been, i) Cobb's angle $<40^{\circ}$; ii) Cobb's angle $>60^{\circ}$. Preoperative SRS 24 satisfaction questionnaires were completed by all the 14 patients, while Cobb's angles and radiological sagittal profiles were measured by qualified radiologists. Preoperative MRI scans were done in all patients to exclude any intraspinal anomaly. The Rib hump was evaluated clinico-radiologically and was corrected by posterior costoplasty in selected cases. Patients routinely followed up at 3, 6 and 12 months in the first year after surgery, and then once a year. At every visit follow up evaluation was performed by measuring the coronal Cobb's angle (anteroposterior view) and evaluating the sagittal balance (lateral view) [figure-1 $(\mathrm{g})$ ]. All the 14 patients filled the SRS 24 satisfaction questionnaire ${ }^{15}$ and Pain status of the patients was evaluated by the Visual Analogue Score (VAS) ${ }^{16}$ in every follow up.

\section{Operative procedure:}

The extent of exposure is determined preoperatively by radiological or fluoroscopic assessment of both the upper and lower target segment and marked over the skin accordingly. All the patients underwent surgery by posterior midline approach but the incision was designed by keeping the postoperative scar in mind. The dissection was carried out meticulously with proper haemostasis upto the transverse processes. The spinous processes were excised, prepared and kept for grafting. The sublaminar spaces are created and cleared by cutting the interspinous ligaments. The midline ligamentum flava was removed with care. The extent of vertebral level involvement is followed according to the basic principles of scoliosis surgery proposed by Goldstein ${ }^{17}$ and Moe ${ }^{18}$. We prefer to involve two vertebra above and below the corresponding upper and lower end vertebra.

After exposure of the sublaminar spaces 20 gauge stainless steel double looped wires are passed at each level in caudal to cephalad direction. The facetal preparation for fusion is performed. The size of Hartshill loop rectangle is measured and adequately contoured. Wires are tied onto the loop rectangle with cephalad wire ends inside the loop rectangle and caudal wire ends outside the loop rectangle at each level. This maneuver is reversed at the lower end of the construct to prevent the caudal migration of the construct. Tightening of concave wires are performed first at each level which causes translation of the curve on to the loop rectangle and then the wires of the convex side is tightened which essentially derotates the curve. All the wires were tightened 1-2 times before final tightening is done. This corrects the spinal deformity onto the loop rectangle [figure-1(f)]. The sublaminar spaces are packed with spongostum. To enhance the posterior fusion process thorough shingling is done over the posterior surface of laminae and graft bed is prepared where bone chips collected from the excised portion of the spinous processes are laid down. The entire wound is irrigated and then closed in layers keeping a drain in situ.

\section{Results:}

All fourteen patients underwent posterior surgery and posterior instrumentation with Hartshill rectangle and sublaminar wiring. Posterior costoplasty was done in two patients. Autogenous bone graft taken from excised spinous process, excised rib mixed with freeze dried 
allograft taken from Savar Atomic energy centre was used in all patients. We used 20 gauge, double looped, precontour stainless steel sublaminar wires and a $6 \mathrm{~mm}$ thick stainless steel spinal rectangle for the spinal instrumentation. As there is un-availability of intraoperative monitoring system of spinal cord, we sometimes used 'wake up' test. Postoperative mobilization was done at an average of 6 days (5 to 12 days). We did not use any postoperative bracing.

Follow- up ranged from 12 to 36 months, the average being 14.5 month. As showed in table-I and figure-2, the mean scoliosis in the coronal plane (Cobb's angle) measured $53.50^{\circ} \pm 03.98^{\circ}$ preoperatively and $18.86^{\circ} \pm 02.86^{\circ}$ postoperatively $(\mathrm{p}<0.05)$. After 1 year of follow up the mean Cobb's angle was $21.14^{\circ} \pm 02.77^{\circ}$ which was statistically significant $(\mathrm{p}<0.05)$ with an average loss of correction of $02.21^{\circ}$. The average correction immediate postoperatively was $32.14^{\circ}$ which reduced to $29.87^{\circ}$ at 1 year follow up. We have observed average $60.58 \%$ correction at 1 year follow up. The younger age group had a better percentage of correction $62.60 \%$ than the $57.85 \%$ correction in older age group. The preoperative mean kyphotic angle was $60.14^{\circ} \pm 07.30^{\circ}$ which was significantly corrected to mean $39.50^{\circ} \pm 02.46^{\circ}(\mathrm{p}<0.05)$ at immediate postoperative period that reduced to $42.14^{\circ} \pm 05.28^{\circ}$ $(\mathrm{p}<0.05)$ with $29.77 \%$ correction at 1 year follow up remaining within the near normal anatomical range and all the cases had a normal balanced spine based on radiological evaluation and one of the case is illustrated in figure 1(a)-(g).

Surgical time for posterior surgery ranged from three hours to four hours 15 minutes (average of three hours and 40 minutes and average blood loss was $800 \mathrm{cc}$. The lower extent of posterior spinal arthrodesis was a L2 $(n=2)$ patients, L3 $(n=5)$ patients, L4 $(n=6)$ patients, L5 $(n=1)$ patients. Total 384 sublaminar wire were introduced in 192 laminar levels. The pain status improved but not significantly from preoperative average of 3.73 to 2.93 at 1 year follow-up. The patients' satisfaction index as per the SRS24 questionnaire in 14 patients revealed that $80.48 \%$ of patients were satisfied and $71.42 \%$ were happy to live with their present back status lifelong. No permanent neurological complication was seen, only transient hyperesthesia developed in $02(14.29 \%)$ patients who were improved after 6 months. Superficial wound infection developed in $01(07.14 \%)$ patient which was managed conservatively. Lower most wire breakage on the right side occurred in $01(07.14 \%)$ patient due to fall on the ground with heavy object over head 15 months after operation but it was asymptomatic and on follow-up.

Table-I

Demographic characteristics, peroperative vertebral level of fixation and postoperative outcome of surgery.

\begin{tabular}{|c|c|c|c|c|c|c|c|c|c|c|c|}
\hline \multirow[t]{2}{*}{$\begin{array}{l}\text { Sl.No. } \\
\text {. }\end{array}$} & \multirow[t]{2}{*}{$\begin{array}{c}\text { Age, Sex } \\
\text { (Type) }\end{array}$} & \multirow[t]{2}{*}{$\begin{array}{l}\text { Type(Side } \\
\text { of curve) }\end{array}$} & \multirow{2}{*}{$\begin{array}{c}\begin{array}{c}\text { Vertebral } \\
\text { level }\end{array} \\
\text { Upper/Lower } \\
\text { (Levels) }\end{array}$} & \multicolumn{3}{|c|}{$\begin{array}{l}\text { Coronal Plane } \\
\text { Angle }\end{array}$} & \multicolumn{3}{|c|}{$\begin{array}{c}\text { Sagittal Plane } \\
\text { Angle }\end{array}$} & \multirow{2}{*}{$\begin{array}{c}\text { VAS } \\
\text { Preop/ } \\
\text { At 1yr }\end{array}$} & \multirow{2}{*}{$\begin{array}{c}\text { Satisfac. } \\
\text { Index } \\
\text { (SRS } \\
24 Q \text { ) }\end{array}$} \\
\hline & & & & Pre op & At $1 \mathrm{yr}$ & $\%$ Curr & Preop & At $1 \mathrm{yr}$ & $\%$ Curr & & \\
\hline 01 & $15 \mathrm{Y}, \mathrm{F}$ & to & $\mathrm{D}_{2} / \mathrm{L}_{5}(16)$ & 5 & 18 & 65.39 & 6 & 42 & 3 & $1 / 3$ & 86.67 \\
\hline 02 & 19Y, F(Idio.) & $\mathrm{TL}(\mathrm{L})$ & $\mathrm{D}_{1} / \mathrm{L}_{4}(16)$ & 60 & 27 & 55.00 & 70 & 48 & 31.43 & $0 / 0$ & 80.00 \\
\hline 03 & 18Y, F(Idio.) & $\mathrm{TL}(\mathrm{R})$ & $\mathrm{D}_{4} / \mathrm{L}_{4}(13)$ & 50 & 22 & 56.00 & 62 & 45 & 27.42 & $2 / 1$ & 86.67 \\
\hline 04 & 19Y, F(Idio.) & $\mathrm{TL}(\mathrm{R})$ & $\mathrm{D}_{4} / \mathrm{L}_{3}(12)$ & 57 & 23 & 59.65 & 65 & 50 & 23.07 & $0 / 0$ & 86.67 \\
\hline 05 & 20Y, F(Idio.) & $\mathrm{TL}(\mathrm{R})$ & $\mathrm{D}_{1} / \mathrm{L}_{3}(15)$ & 60 & 24 & 60.00 & 68 & 48 & 29.41 & $0 / 0$ & 73.33 \\
\hline 06 & 11Y,M(Cong) & $\mathrm{D}(\mathrm{L})$ & $\mathrm{D}_{4} / \mathrm{L}_{2}(11)$ & 55 & 20 & 63.64 & 45 & 35 & 22.22 & $0 / 1$ & 80.00 \\
\hline 07 & 13Y, F(Idio.) & $\mathrm{TL}(\mathrm{R})$ & $\mathrm{D}_{3} / \mathrm{L}_{4}(14)$ & 48 & 18 & 62.50 & 50 & 38 & 24.00 & $0 / 2$ & 80.00 \\
\hline 08 & 18Y,M(Idio.) & $\mathrm{T}$ & $\mathrm{D}_{2} / \mathrm{L}_{4}(15)$ & 55 & 22 & 60.00 & 58 & 40 & 31.03 & $0 / 0$ & 80.00 \\
\hline 09 & 17Y,M(Idio.) & $\mathrm{TL}(\mathrm{R})$ & $\mathrm{D}_{2} / \mathrm{L}_{3}(14)$ & 52 & 20 & 6 & 60 & 45 & 25.00 & $0 / 0$ & 73.33 \\
\hline 10 & 12Y, F(Cong) & $\mathrm{D}(\mathrm{R})$ & $\mathrm{D}_{4} / \mathrm{L}_{2}(11)$ & 50 & 18 & 64.00 & 53 & 33 & 37.74 & $3 / 1$ & 86.67 \\
\hline 11 & 15Y,M(Idio.) & $\mathrm{TL}(\mathrm{L})$ & $\mathrm{D}_{3} / \mathrm{L}_{3}(13)$ & 52 & 20 & 61.54 & 55 & 38 & 30.90 & $0 / 0$ & 80.00 \\
\hline 12 & 18Y, F(Idio.) & $\mathrm{TL}(\mathrm{L})$ & $\mathrm{D}_{3} / \mathrm{L}_{4}(14)$ & 48 & 18 & 62.50 & 60 & 40 & 33.33 & $0 / 0$ & 73.33 \\
\hline 13 & 18Y, F(Idio.) & $\mathrm{TL}(\mathrm{R})$ & $\mathrm{D}_{2} / \mathrm{L}_{4}(15)$ & 52 & 22 & 57.69 & 63 & 40 & 36.50 & $1 / 0$ & 73.33 \\
\hline 14 & 21Y,M(Idio.) & $\mathrm{TL}(\mathrm{R})$ & $\mathrm{D}_{3} / \mathrm{L}_{3}(13)$ & 58 & 24 & 58.62 & 68 & 48 & 29.41 & $0 / 0$ & 86.67 \\
\hline
\end{tabular}




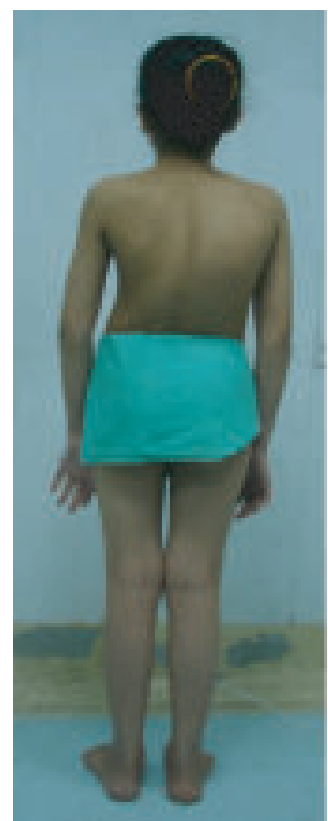

(a)

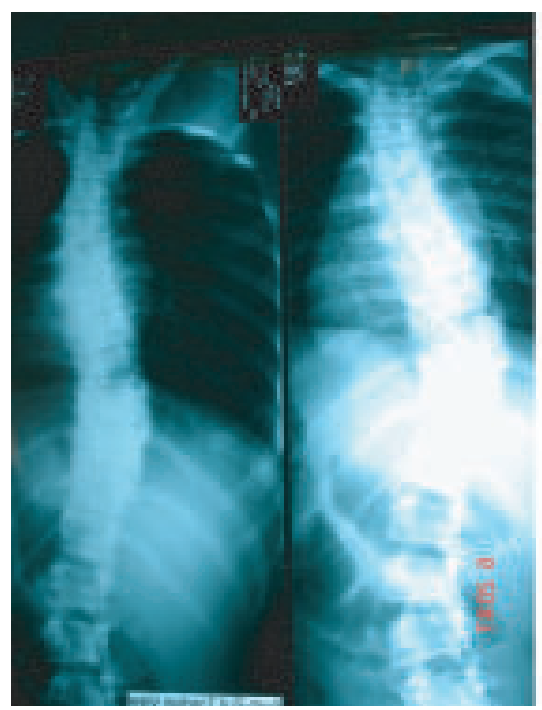

(e)

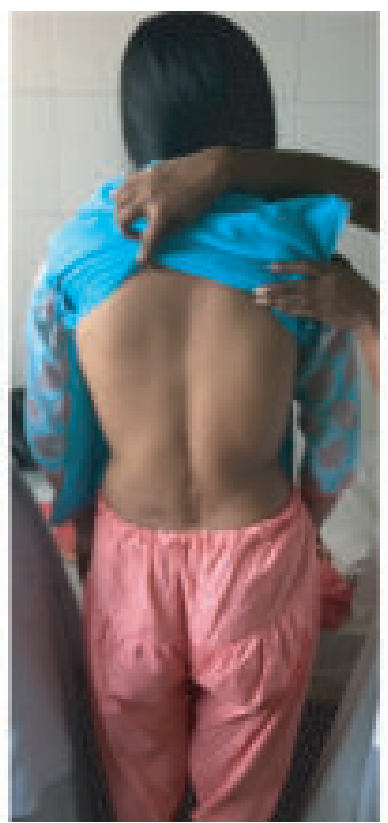

(b)

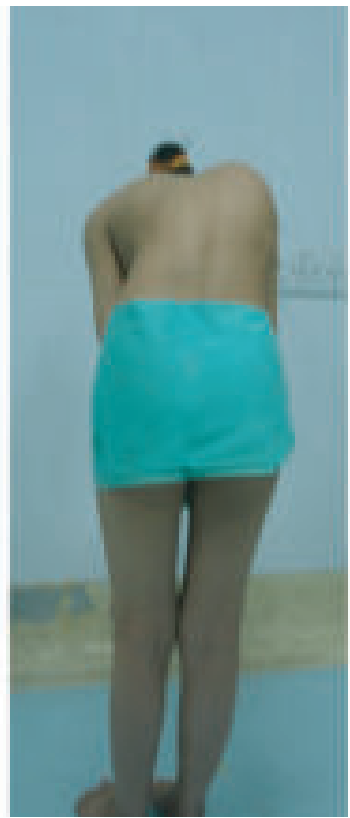

(c)

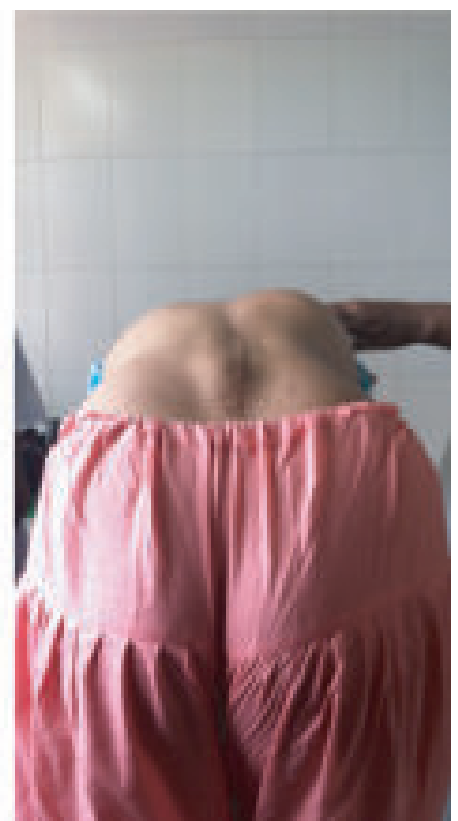

(d)

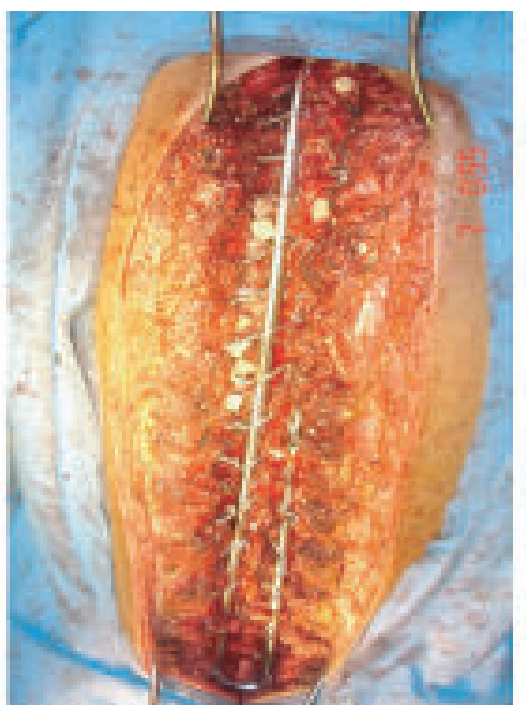

(f)

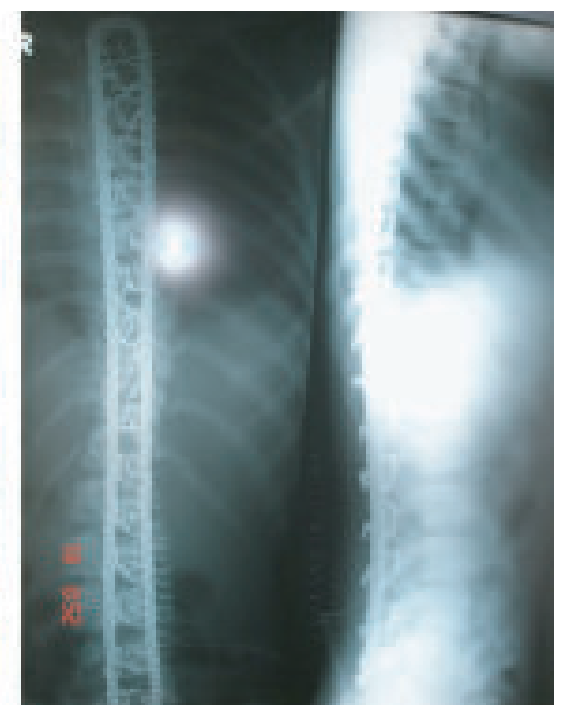

(g)

Fig.-1: Clinical and radiological assessment of scoliotic patients. Preoperative clinical assessment of the patients regarding the curve, flexibility, correctivity and assessment of the rib hump, (a) (c), the postoperarive assessment shows a good cosmetic correction of the deformity (b) (d), the radiological assessment of the spine in standing and bending scoliogram (e), the peroperative view after instrumentation (f) and the postoperative X-ray showing correction of the curve in both sagittal and coronal plane ( $g$ ).

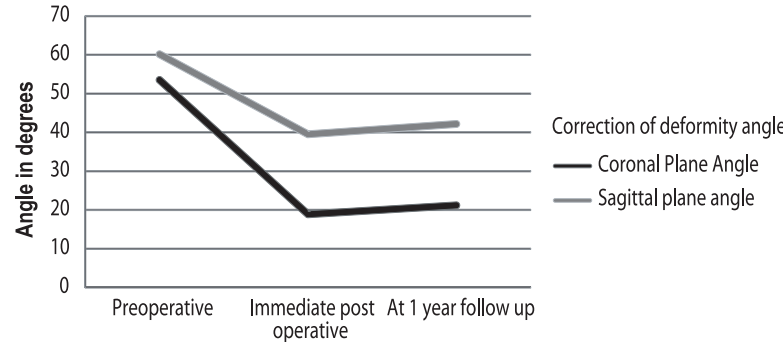

Fig.-2: The change of coronal and sagittal plane angle after surgery.

\section{Discussion:}

There has been a tremendous improvement in the instrumentation techniques for correction of scoliosis. Numerous systems of posterior instrumentation including the Harrington distraction rod, Harrington distraction and compression rods with a transverse loading device, Harrington distraction rods with sublaminar wires and Luque rods with sublaminar wires have been used over the years. Most recent literature still popularizes the use 
of the third generation implants (Cotrel-Dubousset) ${ }^{19,20}$. Although segmental spinal instrumentation, done by sublaminar wiring and Hartshill loop rectangle, had fallen out of favor in comparison to the third generation implants due to various drawbacks, ${ }^{21}$ significant correction and ability to maintain it is still possible in all planes, at a comparatively low cost with this technique. ${ }^{11}$

An ideal system of spinal fixation would have several characteristics. It would be safe and easy, provide rigid fixation and predictable correction with a minimum post operative external support required, be applicable to a wide variety of spinal deformities, and have a high rate of fusion with a low incidence of failure of the instrumention. Segmental Spinal instrumentation with wires appears to meet the majority of these criteria and offers several advantages over other forms of segmental and non segmental fixation. ${ }^{22}$ There is an even distribution in corrective forces, with two lateral fixation points on each segment which provide a good rotatory control. Sagittal plane correction is also comparable to the third generation implants, as care is taken in contouring the loop rectangle before tightening the wires. ${ }^{23,24}$ However, the loop rectangle and wire constructs aim at translation and coronal and sagittal balancing rather than derotation as its principle, so extent of derotation is not the purpose that has been intended to achieve.

As like as the socioeconomic condition, the awareness of availability of surgical solution is not yet well established in our country because of the unavailability of the appropriate surgical set up. We are the only institute in the country performing the deformity surgery with a relatively better anaesthetic facility and surgical setup but most of the cases are late and with advanced deformity. We have observed a large number of patients with advanced deformity (Cobb's angle $>60^{\circ}$ ) in a state where the growth has been already complete, even the operable cases presented late. In our series age ranged from 11 to 23 years and $08(58.14 \%)$ cases presented after the age of 18 years which has been a contrast with study by Herndon et al. ${ }^{22}$ on 63 patients where age ranged from $3 y r s-21 y r s$ and only $15(23.80 \%)$ presenting after 18 years. In a series of 36 patients of Bhojraj et al. ${ }^{11}$ the average age was 14.20 years whereas our series shows $16.71 \pm 03.22$ years which reflects the relative late presentation. Majority of our cases were female (64.28\%) as like that of Benli et al. ${ }^{25}$ and Bhojraj et al. ${ }^{11}$ with $66.66 \%$ and $86.11 \%$ respectively. The right sided convexity of the scoliotic curvature was in 10 cases $71.43 \%$.

The mean scoliosis in the coronal plane (Cobb's angle) measured $53.50^{\circ} \pm 03.98^{\circ}$ pre-operatively and $18.86^{\circ} \pm$ $02.86^{\circ}$ immediate post operatively. We observed average percentage Coronal Cobb's angle correction of $60.58 \%$ which was statistically significant $(\mathrm{p}<0.05)$. In the series of 36 patients Bhojraj et al. ${ }^{11}$ showed $73.25^{\circ}$ preoperative Cobb's angle and $26.12^{\circ}$ immediate postoperatively with average angle of correction is $64.34 \%$. Although we have selected patients with relatively less steep curves the average degree of correction is almost comparable. Studies conducted by Mueller et al. ${ }^{26}$ and Remes et al. ${ }^{27}$ showed $62.50 \%$ and $62-67 \%$ correction which is also comparable to our results, although Benli et al. ${ }^{25}$ showed a larger degree of correction of $79.9^{\circ}$. The loss of correction at 24 months follow-up was $02.21^{\circ}$ which is also comparable to the findings of the study conducted by Bhojraj et al. ${ }^{11}$ who found $2.2^{\circ}$, moreover Herndon et al. ${ }^{22}$ showed range of $0^{\circ}$ $-10^{\circ}$ loss of correction in 2-7 years follow up. The preoperative average kyphotic angle in our series was $60.14^{\circ} \pm 07.30^{\circ}$ which was corrected to average $39.50^{\circ}$ at immediate postoperative period that reduced to $42.14^{\circ} \pm$ $05.28^{\circ}$ with $29.77 \%$ correction at 1 year follow-up. The correction was also statistically significant $(\mathrm{p}<0.05)$ and remaining within the near normal anatomical range. The average correction was $18^{\circ}$ (range $12^{\circ}-25^{\circ}$ ) which is comparable to the study by Bhojraj et al. ${ }^{11}$ where he showed $22.60^{\circ}$ correction with a range of $04^{\circ}-32^{\circ}$. The patients' pain status as assessed by the VAS does not depict a significant change as the same scenario described by other studies. Average preoperative pain score according to VAS was 0.50 that had not been changed even at 1 year follow up. Average pain 4.2 - 4.5 was observed by Bhojraj et al. ${ }^{11}$ which is a little bit higher than ours as because they had surgeries on Neuromuscular Scoliosis which we did not. The patients' satisfaction index as per the SRS24 questionnaire in our 14 patients revealed that $80.48 \%$ of patients were satisfied with the surgery and ready to undergo the same surgery if required. On, whether they were happy to live with their present back status lifelong, $71.42 \%$ agreed. This observation is also comparable to Bhojraj et al. ${ }^{11}$

Neurological deficit rates up to $17 \%$ have been reported with sublaminar wiring. ${ }^{28,29}$ The SRS Committee has reported neurological deficit risk to be $0.03 \%{ }^{30}$ Asher $^{31}$ reported neurological deficit score as $0.03 \%$ in his series of 355 patients, but Benli et al. ${ }^{25}$ have reported no neurological deficit in patients operated with ISOLA Instrumentation. In our study no neurological deficit has been observed with sublaminar wiring, only 02 (14.29\%) cases developed transient hyperaesthesia which was improved after 06 months. We have observed only 01 $(07.14 \%)$ case developing superficial wound infection which was improved by conservative measures. Asher ${ }^{31}$ reported $1-2 \%$ early and $1 \%$ late infection rate in his series and Richards et al. ${ }^{32}$ reported $10 \%$ late infection rate that was managed with debridement. We observed only 01 
wire breakage whereas Bhojraj et al. ${ }^{11}$ had 06 broken wires and none of them needed re-exploration as they were asymptomatic as like as ours.

\section{Conclusion:}

Overall outcome in segmental spinal fixation with sublaminar wire and hartshill rectangle were satisfactory. No decompensation and imbalance have been observed and almost totally balanced vertebral column has been obtained in all patients. Given these results, in our opinion, this technique is a successful alternative and effective modality of treatment for scoliotic patients where advanced surgical options are not available or attainable.

\section{References:}

1. Dickson RA, Lawton JO, Archer IA, Butt WP. The pathogenesis of idiopathic scoliosis: Biplanar spinal asymmetry. J Bone Joint Surg Br. 1984; 66(1): 8-15.

2. Eisenstein S, Tuli S, Govender S. The back. In: Solomon L, Warwick DJ, Nayagam S, editor. Apley's System of Orthopaedics and Fractures. $9^{\text {th }}$ ed. Hodder Arnold, London, 2010, p. 371403.

3. Weiss HR. Is there a body of evidence for the treatment of patients with Adolescent Idiopathic Scoliosis (AIS)? Scoliosis 2007; 2: 19 .

4. Harrington PR. Treatment of scoliosis: Correction and internal fixation by spine instrumentation. J Bone Joint Surg Am. 1962; 44-A: 591-610.

5. Sengupta DK, Webb JK. Scoliosis: The current concepts. Indian J Orthop. 2010; 44(1): 5-8.

6. Resina J, Ferreira A. A technique for correction of scoliosis. $J$ Bone Joint Surg Br. 1977; 59: 159-165.

7. Broom MJ, Banta JV, Renshaw TS. Spinal fusion augmented by Luque instrumentation for neuromuscular scoliosis. $J$ Bone Joint Surg Am. 1981; 71: 32-42.

8. Luque ER, Cardozo A. Segmental correction of scoliosis with rigid internal fixation. Orthop Trans. 1977; 1: 136.

9. Dove J. Internal fixation of lumbar spine. Clin Orthop Relat Res. 1986; 203: 135-140.

10. Aaro S, Dahlborn M. The effect of Harrington instrumentation on the longitudinal axis of rotation of the apical vertebra and on the spinal and rib-cage deformity in idiopathic scoliosis studied by computer tomography. Spine 1982; 7: 457-462.

11. Bhojraj SY, Varma RG, Nene AM, Mohite SB. Spinal loop rectangle and sub laminar wiring as a technique for scoliosis correction. Indian J Orthop. 2010; 44: 50-56.

12. Sullivan JA, Stephen C. Segmental Spinal Instrumentation by Laminar Wiring. Orthop. Trans. 1981; 5: 17.

13. Taddonio RF, Karin W, Marc A. A Comparison of Patients with Idiopathic Scoliosis Managed with and without Postoperative Immobilization following Segmental Spinal Instrumentation with Luque Rods. A Preliminary Report. Orthop. Trans. 1984; 8: 172.

14. Thompson GH, Wilber RG, Shaffer JW, Nash CL. Segmental Spinal Instrumentation in Spinal Deformities. Orthop. Trans. 1984; 8: 82 .
15. Haher TR, Gorup JM, Shin TM, Homel P, Merola AA, Grogan DP, et al. Results of the scoliosis research society instrument for evaluation of surgical outcome in adolescentidiopathic scoliosis. Spine 1999; 24: 1435-1440.

16. Guyatt GH, Townsend M, Berman LB, Keller JL. A comparison of Likert and visual analogue scales for measuring change in function. J Chronic Dis. 1987; 40: 1129-1133.

17. Goldstein LA. The surgical management of scoliosis. Clin Orthop Relat Res. 1964; 35: 95-115.

18. Moe JH. Methods of correction and surgical techniques in scoliosis. Orthop Clin North Am. 1972; 3: 17-48.

19. Dubouset J, Cotrel Y, Technique D osteosynthesis raquidienne segmentaire parvoie postrieure. Rev Chi Orthop. 1984; 70: 489-495.

20. Dubouset J, Three dimensional analysis of scoliotic deformity. In: Weinstein SL, editor. The pediatric spine: Principles and practice. New York: Raven Press; 1994, p. 487-496.

21. Wilber RG, Thompson GH, Shaffer JW, Brown RH, Nash CL Jr. Postoperative neurological deficits in segmental spinal instrumentation. J Bone Joint Surg Am. 1984; 66: 11781187.

22. Herndon WA, Sullivan JA, Yngve DA, Gross RH, Dreher G.: Segmental spinal instrumentation with sublaminar wires. A critical appraisal. J Bone Joint Surg Am. 1987; 69: 851-859.

23. Winter RB, Lonstein JE. Adult Idiopathic Scoliosis treated with Luque or Harrington Rods and Sublaminar wiring. J Bone Joint Surg Am. 1989; 71: 1308-1313.

24. Oheneba BA, Lonstein JE, Winter RB, Koop S, Brink KV, Denis F. Management of neuromuscular spine deformities with luque segmental instrumentation. $J$ Bone Joint Surg Am 1989; 71: 548-562.

25. Benli L, Akalin S, Aydin E, Baz A, Citak M, Kýs M, Duman E. Isola spinal instrumentation system for idiopathic scoliosis. Arch Orthop Trauma Surg 2001; 121:17-25.

26. Mueller FJ, Gluch H. Adolescent idiopathic scoliosis (AIS) treated with arthrodesis and posterior titanium instrumentation: 8 to 12 years follow up without late infection. Scoliosis 2009; 4: 16.

27. Remes V, Helenius I, Schlenzka D, Yrjonen T, Ylikoski M, Poussa M. Cotrel-Dubousset (CD) or Universal Spine System (USS) instrumentation in adolescent idiopathic scoliosis (AIS): Comparison of midterm clinical, functional, and radiologic outcomes. Spine (Phila Pa 1976) 2004; 29: 2024-2030.

28. Herring JA, Wenger DR. Segmental spinal instrumentation. Spine 1982; 7: 285.

29. Winter RB. Spine update: Neurological safety in spinal deformity surgery, Spine 1997; 22: 1527-1533.

30. Lowe TG. Morbidity and mortality report of the SRS, 1987; Vancouver, Canada.

31. Asher M, Lai S, Burton P, Manme D, Cooper A. Safety and efficacy of Isola instrumentation and arthrodesis for adolescent idiopathic scoliosis. Spine 2004; 29 (18): 2013-23.

32. Richard BS, Herring BA, Johnston CE et al. Treatment of adolescent idiopathic scoliosis using TSRH. Spine 1994; 19:598. 